\title{
Study of the Regeneration Cleaning of Used Mineral Oils - Ecotoxicological Properties and Biodegradation
}

\author{
H. Hybská,, ${ }^{a, *}$ V. Vel'ková, ${ }^{b}$ D. Samešová, ${ }^{a}$ J. Fialová, a and M. Kučera ${ }^{c}$ \\ aDepartment of Environmental Engineering \\ ${ }^{b}$ Department of Fire Protection \\ 'Department of Mechanics, Mechanical Engineering and Design: \\ Technical University in Zvolen, T. G. Masaryka 24, \\ 96053 Zvolen, Slovakia \\ 96053 Zvolen, Slovakia
}

doi: 10.15255/CABEQ.2017.1109

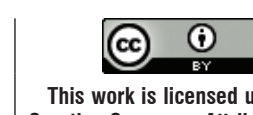

Creative Commons Attribution 4.0 International License

\author{
Original scientific paper \\ Received: March 2, 2017 \\ Accepted: November 13, 2017
}

The aim of the study was to establish and compare the model of the biodegradability and ecotoxicological properties of oil samples in aqueous environment. The unused new mineral oil Turbinol and used (after 1 year of usage) recovered oil Turbinol purified by the electrostatical method were the tested samples. For the determination of the ecotoxicological properties, the test organisms used were seeds of Sinapis alba L. and the small aquatic crustaceans Daphnia magna. Preliminary tests were positive and determined the acute toxicity with the values of $\mathrm{IC}_{50}$ and $\mathrm{EC}_{50}$. Biodegradability was determined by the manometric method, in tests which lasted 28 days. Tests of toxicity were positive, and the samples were found to be hard to biodegrade. Determination of the oil composition by gas chromatography with mass detection (GC - MS); found that the composition of the electrostatically cleaned oil is comparable to the new oil, which is confirmed by the results obtained with the response inhibition in selected tests. Regeneration extends the oil life, reducing the cost of disposal of waste oils, saving fossil raw materials, thus belonging to the environmentally friendly techniques.

Key words:

mineral oil, electrostatical method, biodegradation, ecotoxicity, gas chromatography

\section{Introduction}

Mineral oils are applied in almost every industry. They are substances of petroleum origin formed by mixture of higher hydrocarbons with the addition of special substances. The release of these substances is dangerous for all components of the environment. Moreover, the pollution of air, soil, or water may occur by leakage from equipment or mishandling. ${ }^{1,2}$

From such perspective, the largest contamination caused by mineral oils can be observed in industry and transport. They are used in machines, engines, vehicles, hydraulic and transmission systems, and so on, where they have the secondary function of providing lubrication and cooling. ${ }^{3,4}$ Generally, mineral oil is affected by processes of mechanical stress, great changes in temperature and other physical and chemical processes, which may result in changes in their composition and properties. Petroleum is a non-renewable resource and therefore, research and development activities focus on the re-use of previously used oil products, which would otherwise end up in landfills of hazardous

"Corresponding author, e-mail: hybska@tuzvo.sk; Tel. +421455206488 waste. Today, we know many effective and relatively inexpensive methods for recycling and regeneration of used petroleum oils. The basic physical and chemical characteristics of mineral oil can be changed to the same level as new oils. Disposal of wastes is potentially hazardous for theenvironment. The disposal of oil is an expensive process requiring financial resources. The combustion of oils has a negative impact on air quality, and therefore on ecosystems, and it has significant negative impacts on human health. ${ }^{5}$ Many components of mineral oils are considered carcinogenic, meaning that is important to know about the determination and the persistence of these substances in nature. ${ }^{6}$ In view of the incineration of waste or other substances such as fuels, it is necessary to analyse the issues related to air pollution very carefully.?

The acceptable limit concentration of these compounds can be determined using suitably selected bioassays on sensitive organisms. The characteristics of xenobiotics in relation to environment can be used to assess their ecotoxicological properties. Ecotoxicological studies have shown the harmful impact of chemical substances on live organisms and environment. ${ }^{8}$ Acute and chronic toxicity tests are the principal means of assessing their activities. 
The effects of specific chemical compounds can be evaluated by using test organisms, such as fish, daphnia, rats, birds, and seeds. ${ }^{9,10}$ Given their low cost and good sensitivity, the germination of seeds can be used in important toxicological tests, and is also a practical source of information to assess the impact of toxic substances and organic inhibitors. This issue is addressed in the study by Lopes et $a l .{ }^{11}$, who evaluated the behaviour of different types of automotive lubricating oils on the environment.

Tamada et al. ${ }^{12}$ investigated the biodegradability of lubricating oils through respirometric tests and toxicological tests by comparing their different levels of toxicity. The tests were performed using earthworms (Eisenia andrei), rocket seeds (Eruca sativa) and lettuce seeds (Lactuca sativa) in mineral, synthetic lubricating oil, investigating different periods of their biodegradation in the soil. Tests of toxicity were used for the indirect measurement of the biodegradation of the pollutants. Mineral and synthetic oils are effectively metabolized in soil, even if their toxicity has not completely disappeared after 180 days.

The behaviour of lubricating oils in the environment is a source for the development of new liquids. There has been a trend to study lubricants with a lower impact on the environment and rapid biodegradation effects, focusing on the development of synthetic and semi-synthetic lubricating oils. ${ }^{13}$

Cecutti and Agius $^{14}$ presented the results of their study in which they successfully implemented tests on organisms such as algae, daphnia and fish to determine the ecotoxicological properties of various oils, including new bio-oils, before use and after 1000 hours of use in an aqueous environment. They found that the fish responded well in all samples without distinction and $\mathrm{LC}_{50}$ after 48 hours was $>10000 \mathrm{mg} \mathrm{L}^{-1}$. It was the most sensitive bioassay with algae that allowed the classification and comparison of the samples. The tests with daphnia also provided excellent results. It was found that samples of mineral origin showed acceptable results in the organic products, and it was of interest that the $\mathrm{EC}_{50}$ in the samples with the new oil was $5450 \mathrm{mg} \mathrm{L}^{-1}$ compared with $2450 \mathrm{mg} \mathrm{L}^{-1}$ in used oil.

In the event of contamination of the aquatic environment by petroleum products from anthropogenic activities, which include the above-mentioned mineral oils, activation of the microorganisms present in the water, and their role in the degradation of toxic substances is possible when the concentration of toxic substances in the environment is below a certain level, and when there are suitable physical conditions. ${ }^{15}$

Biodegradability of lubricants was evaluated through respirometric tests, and toxicological tests were carried out to assess their toxicity before and after use. All the lubricants showed toxicity after biodegradation. Used car lubricants are highly toxic because of the presence of a high concentration of polycyclic aromatic hydrocarbons, which are known to be potential carcinogens. ${ }^{16}$

Researchers from the University of Oulu (Finland), Department of Process and Environmental Engineering, have studied biodegradable motor oil in groundwater. They used the manometric respiratory method. ${ }^{17}$ The results demonstrated that biodegradation progresses more rapidly in a mineral-rich medium (soil samples were analyzed for the composition of micro and macroelements). The degradation process undoubtedly affects the amount of nitrogen in the soil. In the samples of groundwater, the oil caused a serious environmental risk because of its low biodegradability. From the results and comparison with a standard method, the suitability of the use of the respiratory manometric method has been demonstrated. ${ }^{18}$

Lopes et al. ${ }^{11}$ examined the biodegradability of control (T1), synthetic (T2), mineral (T3), and used (T4) oil by applying the respirometric method. The results pointed to a downward trend in $\mathrm{CO}_{2}$ production in Bartha and Pramer respirators in the order $\mathrm{T} 4>\mathrm{T} 2>\mathrm{T} 3>\mathrm{T} 1$. This means that the used lubricant oil had the highest biodegradation, followed by the synthetic oil, while mineral oil had the lowest biodegradation. It was also observed that the mineral oil required an extended period of adaptation compared to synthetic oil.

In this study, we deal with the assessment of the composition, ecotoxicological properties, and biodegradability of electrostatically cleaned oil, and compare it with the unused (new) and used (worn) turbine oil Turbinol X-EP 46 in an aquatic environment.

\section{Materials and methods}

\section{Preparation of model samples}

The assays were carried out in model samples that were prepared with surface water contaminated by oil. The concentration of the oil in the water was $1 \mathrm{~g} \mathrm{~L}^{-1}$. As the contaminant, the turbine mineral oil X-EP 46 was used, which consists of hydrogenated base oils and specially selected additives, providing very high oxidation stability. The oil is intended for use in turbines and associated equipment. ${ }^{19}$ The oils used in the assay were new oil, oil used for one year in operation, and oil regenerated by the electrostatic cleaning method, using the device ELC-R6PSP by the company KLEENTEK Slovakia and the Technical University in Zvolen, Department of Forest Har- 
vesting. ${ }^{20}$ The surface water used in the assays was from a flowing natural resource and satisfied the quality requirements for surface waters under Government Regulation No. 269/2010 ${ }^{21}$ Coll. Annex 1 requirements for surface water quality. For evaluation of the results, the program STATISTICA was used. The software STATISTICA 10, ANOVA Single Factor Dispersion Analysis was used to evaluate the results of the ecotoxicological tests. The graphical presentation of ANOVA was performed using $95 \%$ confidence intervals for average immobilization and inhibition values for individual samples.

\section{Principle of electrostatic cleaning}

Electrostatic oil cleaning is completely different from the so far used mechanical methods of filtration, particularly in terms of the impurities from the electrical point of view. It is assumed that only three kinds of dirt exist: positively charged particles, negatively charged particles, and electrically neutral particles. The basic principle of separation of these particles uses electrostatic cleaning equipment for electrophoresis and dielectrophoresis, based on the physical principle of Coulomb's law. ${ }^{22}$ When we let the oil flow through the electric field, specially shaped non-conductive collectors (placed between high-voltage electrodes) capture all the particles in the oil, irrespective of whether they are metallic or non-metallic, conductive or non-conductive, organic or inorganic, including water droplets. During this electrostatic cleaning, the oil becomes charged, but this uses the charge of the particles suspended in the oil. According to the particle size, the charge can be amended only to the speed of the separation of oppositely charged electrodes. ${ }^{20}$

\section{Methods for determining acute ecotoxicity}

For the determination of ecotoxicological properties, two bioassays were conducted according to STN EN $838303^{23}$ : a test of the growth inhibition of the Sinapis alba root and a test of acute toxicity on daphnia (Daphnia magna).

\section{Test of the growth inhibition of the Sinapis alba root}

The test consists of the cultivation of seeds on pads soaked in solutions of the tested substance in comparison with seeds growing on a pad soaked in diluent water. Mustard is representative of cultural crops and higher plants in the toxicity tests. The test conditions are shown in Table 2.

From solutions No. 1-4 (Table 1), a dose of $10 \mathrm{~mL}$ was added to a volumetric flask with a capacity of $1 \mathrm{~L}$ and the solution was refilled with distilled (deionised) water up to the mark and used as
Table 1 -Stock solutions for reconstituted water

\begin{tabular}{ccc}
\hline $\begin{array}{c}\text { Stock } \\
\text { solution }\end{array}$ & Chemical substance & $\begin{array}{c}\text { Concentration of stock } \\
\text { solution }\left(\mathrm{g} \mathrm{L}^{-1}\right)\end{array}$ \\
\hline 1 & $\mathrm{CaCl}_{2} \cdot 2 \mathrm{H}_{2} \mathrm{O}$, p.a. & 117.6 \\
2 & $\mathrm{MgSO}_{4} \cdot 7 \mathrm{H}_{2} \mathrm{O}$, p.a. & 49.3 \\
3 & $\mathrm{NaHCO}_{3}$, p.a. & 25.9 \\
4 & KCl, p.a. & 2.3 \\
\hline
\end{tabular}

Table 2 - Conditions of growth inhibition test of Sinapis alba root

Testing organism Sinapis alba, germination $>90 \%$, per 30 seeds of Sinapis alba L. in Petri dishes

Sample volume $10 \mathrm{~mL}$

Temperature $\quad 20^{\circ} \mathrm{C} \pm 1{ }^{\circ} \mathrm{C}$, thermostat TS $606 \mathrm{CZ} / 2$-Var (WTW, Germany).

Control Reconstituted water (Table 1)

Validity of the Germination in control sample $=99.8 \%$ test (limit $\geq 90 \%$ )

Reference $\quad \mathrm{K}_{2} \mathrm{Cr}_{2} \mathrm{O}_{7}, \mathrm{IC}_{50}, 72$ hours $=23.5 \mathrm{mg} \mathrm{L}^{-1}$ substance (limit $4.1-85 \mathrm{mg} \mathrm{L}^{-1}$ )

Measuring root Steel calibrated measuring instrument

length

Exposure time 72 hours

Response Growth inhibition of Sinapis alba root monitored compared with the control, $\mathrm{IC}_{50}$

a control. The $\mathrm{pH}$ of the diluent water should vary around 7.6-8.0.

Inhibition (stimulation) $\mathrm{I}_{\mathrm{i}}$ of the roots growth of higher plants is calculated using the equation $\mathrm{I}_{\mathrm{i}}(\%)$ $=\left(\mathrm{L}_{\mathrm{C}}-\mathrm{L}_{\mathrm{S}} / \mathrm{L}_{\mathrm{C}}\right) \cdot 100\left(\right.$ Eq. 1), where $\mathrm{L}_{\mathrm{S}}$ is the average length of the root in the tested concentration of aqueous leachate in $\mathrm{cm}$, and $\mathrm{L}_{\mathrm{C}}$ is the average length of the root in the control in $\mathrm{cm}$.

\section{Acute toxicity test on daphnia (Daphnia magna)}

The test is based on monitoring the immobilization of individuals that were exposed to the samples of water contaminated with oil during 48-hour exposure each, in accordance with the conditions specified in Table 3 . The diluting water for the determination of ecotoxicity is prepared by pipetting $2.5 \mathrm{~mL}$ from solutions 1 to 4 into a 1-litre volumetric flask and refilling with demineralised water up to the mark. The prepared diluent water must have a $\mathrm{pH}$ of $7.8 \pm 1.2$ and a concentration of dissolved oxygen greater than $7 \mathrm{mg} \mathrm{L}^{-1}$.

\section{Determination of aerobic biodegradation by the manometer respiratory method}

According to the law of the Slovak Republic no. 67/2010 Coll. Law on conditions for placing 
Table 3 -Conditions of acute toxicity test on daphnia

\begin{tabular}{ll}
\hline $\begin{array}{l}\text { Testing organisms } \\
\text { Age of organism }\end{array}$ & $\begin{array}{l}\text { Daphnia magna } \\
\text { Daphnia younger than 24 hours }\end{array}$ \\
$\begin{array}{l}\text { Reference } \\
\text { substance }\end{array}$ & $\begin{array}{l}\mathrm{K}_{2} \mathrm{Cr}_{2} \mathrm{O}_{7}, \mathrm{EC}_{50}, 48 \text { hours }=0.8 \mathrm{mg} \mathrm{L}^{-1} \\
\left(\text { limit } 0.3-1.5 \mathrm{mg} \mathrm{L}^{-1}\right)\end{array}$ \\
Sample volume & $10 \mathrm{~mL}$ \\
$\begin{array}{l}\text { Temperature } \\
\text { pH }\end{array}$ & $20{ }^{\circ} \mathrm{C} \pm 2{ }^{\circ} \mathrm{C}$ \\
Exposure time & $48 \pm 0.2$ \\
$\begin{array}{l}\text { Response } \\
\text { monitored }\end{array}$ & $\begin{array}{l}\% \text { of the immobilized individuals } \\
\text { compared to the control EC }\end{array}$ \\
temperature, dissolved $\mathrm{O}_{2}$
\end{tabular}

chemical substances and mixtures on the market and on amendments to certain acts ${ }^{24}$, the biodegradability of substances in water sparingly soluble, as well as petroleum oil contaminants in water, is to be determined by a suitable respirometric test. Vähäoja et al. ${ }^{25}$ focus on the biodegradability measurements of tall oil-based wood preservatives and their raw materials in groundwater as determined by the respirometric BOD OxiTop method. Certain substances were also analyzed in standard conditions described by OECD 301 E. The respiratory measurement is based on measuring changes in pressure in a closed sampling bottle. The laboratory equipment OxiTop ${ }^{\circledR}$ Control collects pressure values and allows further processing. The interpretation of the pressure change over time depends on the measured medium, sample preparation, and manipulation during measurement. The laboratory equipment consists of a tray with a stirrer, pressure plugs OxiTop-C, dark glass bottles, and controller OxiTop OC110. The recorded values are processed using the computer software Achat. The biodegrad- ability of the test substance is determined as the \% degradation of the dissolved oxygen in the sample after 28 days. ${ }^{17}$

\section{Determination of the composition of oil samples}

Determination of the composition of the oil sample was done by means of gas chromatography (GC-MS) with mass detection using the instrument AGILENT 5975C. Identification of substances consisted of comparing the mass spectra of the samples with a range of substances from the NIST spectral library. The analytical samples were adjusted by multiple extraction with methanol and hexane as the solvent. ${ }^{26}$

\section{Results and discussion}

\section{Determination of the composition by GC - MS}

The chromatogram in Figure 1 illustrates the individual analytes - samples in the form of chromatographic peaks (zones), where $\mathbf{1}$ is indicates used oil, $\mathbf{2}$ is new oil, and $\mathbf{3}$ is electrostatically regenerated oil. In an ideal regeneration process, undesirable substances are removed from the used mineral oil to the fullest extent possible without altering their hydrocarbon composition ${ }^{27}$, as confirmed by this chromatogram.

\section{Test of acute toxicity on Daphnia magna}

For testing, we used aquatic organisms Daphnia magna Straus, which were laboratory animals from acyclic generations generated by parthenogenesis and bred individuals. The preliminary test of acute toxicity on daphnia was positive (positive in terms of causing death or immobilisation of $\geq 50 \%$ of daphnias during the test when compared to the control), at which time it was necessary to specify the value of $\mathrm{EC}_{50}$. In the basic test, six concentra-

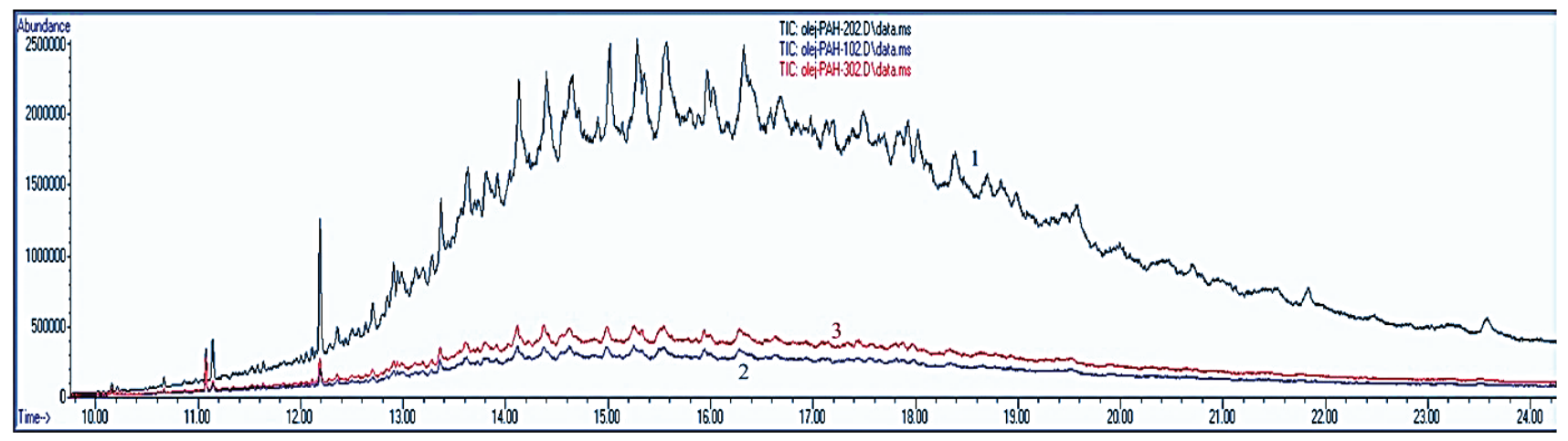

Fig. 1 - Chromatogram (Note: 1 - used oil, 2 -new oil, 3 - oil after regeneration, axis $x$ - Time, axis y-Abundance) 
tions were tested: $200,40,20,10,6.7$, and $5 \mathrm{mg} \mathrm{L}^{-1}$ ( $\mathrm{mg}$ of mineral oil diluted in $1 \mathrm{~L}$ of leachate water). Just as in the experimental samples, a control test

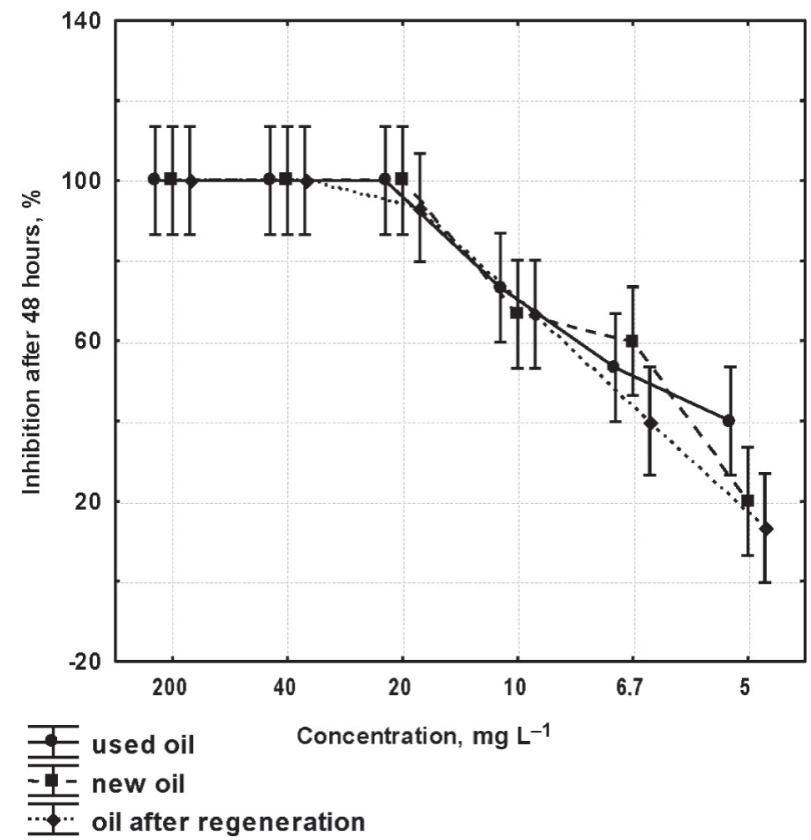

Fig. 2 -Dependence of concentration and immobilisation after 48 hours - test of acute toxicity on Daphnia magna was conducted to validate the results where the test was performed with a reference substance, potassium dichromate, instead of leachate water. After the test, the percentage of immobilisation of daphnia in the samples was calculated. Figure 2 graphically illustrates the $\%$ immobilisation depending on the concentration of the samples after the 48-hour test period, and the basic statistical characteristics are shown in Table 4.

The highest percentage of immobilisation was observed in all samples with the highest tested concentrations. Regression analysis was used to calculate $\mathrm{EC}_{50}$ for each of the oil samples. The results are presented in Table 5, showing that $50 \%$ of individuals will be immobilised in a solution of contaminated recovered oil at a concentration of 8.17 $\mathrm{mg} \mathrm{\textrm {L } ^ { - 1 }}$, which is the most favourable outcome in the test samples, even if they are toxic. The high values of immobilisation are caused by the film that formed on the surface, preventing oxidation of the samples from the outside.

\section{Growth inhibition test of cultivated Sinapis alba root}

Firstly, a preliminary test of the Sinapis alba root inhibition was conducted to model surface wa-

Table 4 - Basic statistical characteristics of acute toxicity test results of Daphnia magna

\begin{tabular}{|c|c|c|c|c|c|}
\hline \multirow{2}{*}{$\begin{array}{l}\text { Sample concentration } \\
\qquad\left(\mathrm{mg} \mathrm{L}^{-1}\right)\end{array}$} & \multirow{2}{*}{ Mineral oil Turbinol } & \multirow{2}{*}{$\begin{array}{c}\text { Average EC } \\
(\%)\end{array}$} & \multicolumn{2}{|c|}{ Confidence intervals } & \multirow{2}{*}{ Standard deviation } \\
\hline & & & $-95.00 \%$ & $+95.00 \%$ & \\
\hline \multirow{3}{*}{200} & Used & 100.00 & - & - & 0.00 \\
\hline & New & 100.00 & - & - & 0.00 \\
\hline & After regeneration & 100.00 & - & - & 0.00 \\
\hline \multirow{3}{*}{40} & Used & 100.00 & - & - & 0.00 \\
\hline & New & 100.00 & - & - & 0,00 \\
\hline & After regeneration & 100.00 & - & - & 0.00 \\
\hline \multirow{3}{*}{20} & Used & 100.00 & - & - & 0.00 \\
\hline & New & 100.00 & - & - & 0.00 \\
\hline & After regeneration & 93.33 & 64.65 & 122.02 & 11.55 \\
\hline \multirow{3}{*}{10} & Used & 73.33 & 44.65 & 102.02 & 11.55 \\
\hline & New & 66.67 & 37.98 & 95.35 & 11.55 \\
\hline & After regeneration & 66.67 & 37.98 & 95.35 & 11.55 \\
\hline \multirow{3}{*}{6.7} & Used & 53.33 & -22.56 & 129.22 & 30.55 \\
\hline & New & 60.00 & 10.32 & 109.68 & 20.00 \\
\hline & After regeneration & 40.00 & -9.68 & 89.68 & 20.00 \\
\hline \multirow{3}{*}{5} & Used & 40.00 & - & - & 0.00 \\
\hline & New & 20.00 & - & - & 0.00 \\
\hline & After regeneration & 13.33 & -15.35 & 42.02 & 11.55 \\
\hline
\end{tabular}


Table 5 - Test of acute toxicity on Daphnia - calculation of EC

\begin{tabular}{c|c|c|c|c|c|c}
\hline Time & Mineral oil Turbinol & Statistical model & $A$ & $k$ & $n$ & $\mathrm{EC}_{50}\left(\mathrm{mg} \mathrm{L}^{-1}\right)$ \\
\hline \multirow{4}{*}{48 hours } & Used & $y=A \cdot\left(1-\exp \left(-(k) \cdot x^{\wedge}(n)\right)\right)$ & 100 & 0.047991 & 1.45457 & 6.27 \\
& New & $y=A \cdot\left(1-\exp \left(-(k) \cdot x^{\wedge}(n)\right)\right)$ & 100 & 0.019042 & 1.83027 & 7.13 \\
& After regeneration & $y=A \cdot\left(1-\exp \left(-(k) \cdot x^{\wedge}(n)\right)\right)$ & 100 & 0.004064 & 2.44678 & 8.17 \\
\hline
\end{tabular}

Note: $A$ - inhibition at zero concentration; $k$ - steepness of decline; $n$ - curvature parameter

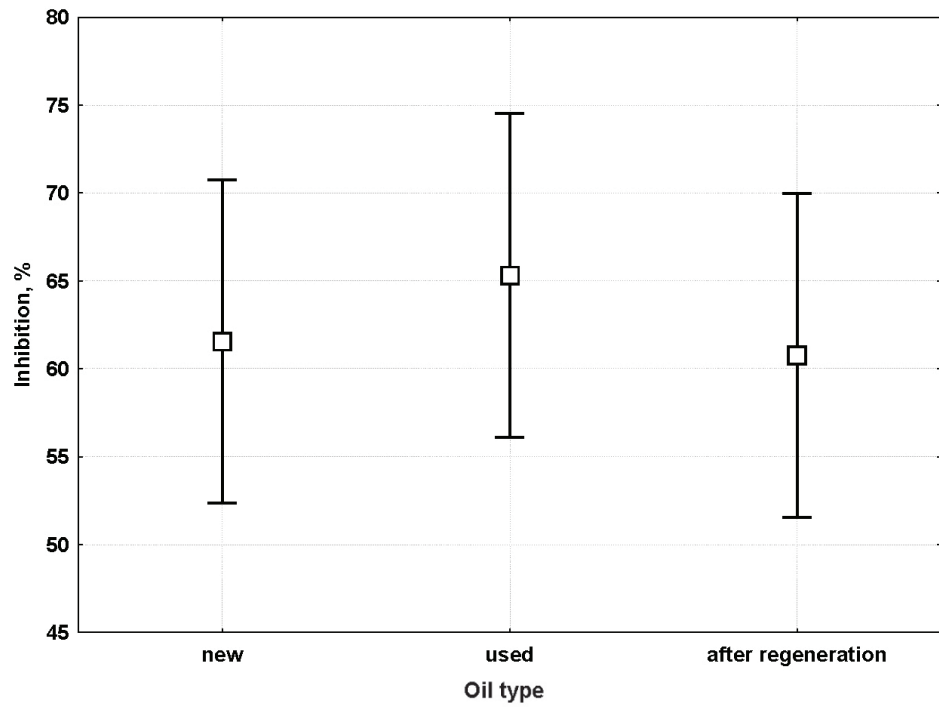

Fig. 3 - Results of the preliminary growth inhibition test of Sinapis alba root

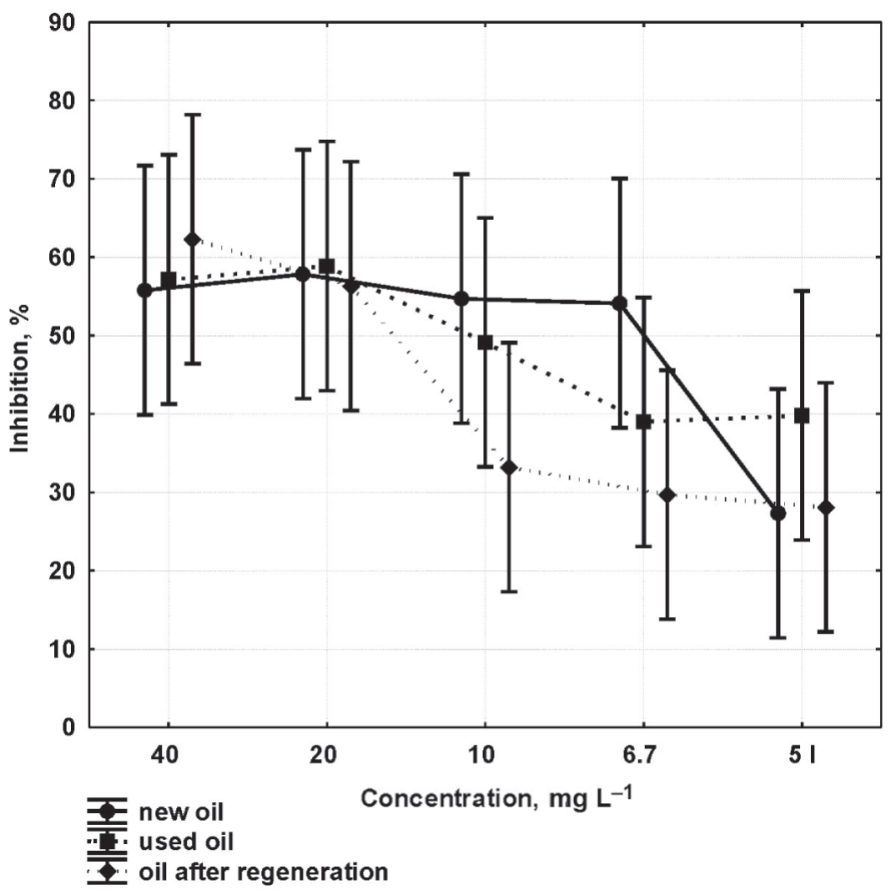

Fig. 4 - Dependence of \% inhibition and concentration for each type of oil

ter contaminated with mineral oil Turbinol X-EP with a concentration of $1 \mathrm{~g} \mathrm{~L}^{-1}$. The Sinapis alba seeds were germinated $99.8 \%$. After 72 hours of incubation under the conditions in Table 2, the length of the roots was measured, from which the inhibition of Sinapis alba root growth was calculated (Eq. 1). The results are presented in Figure 3.

The preliminary test for growth inhibition of Sinapis alba roots compared to the control was positive in all samples. The percentage of inhibition was greater than $30 \%(65.30 \%$ in the water sample with used oil, $61.55 \%$ in the sample contaminated with new oil, and $60.75 \%$ in the sample with recovered oil).

In all samples, the inhibition was greater than $50 \%$, and therefore, a baseline test was conducted to determine $\mathrm{IC}_{50}{ }^{23}$ The basic test used the same dilution series of model samples as in the case of the acute toxicity tests with Daphnia without 200 $\mathrm{mg} \mathrm{L}^{-1}$. The test was conducted under the same conditions as the preliminary test. At the same time, a control was tested, where the sample used leachate water instead of dilution water.

The results of the evaluation are shown in Figure 4 , and the basic statistical characteristics are shown in Table 6.

From Figure 4, it is apparent that there is a significant relation between the $\%$ inhibition and the quantity of contaminant (oil) in the sample. We found that a gentle film of oil formed on the surface of the Sinapis alba seeds in the samples. The mineral oil is almost insoluble in water and is less dense than water, which implies that this caused a significant inhibitory effect.

Regression analysis of the measured values was used to calculate the $\mathrm{IC}_{50}$, from which it followed that in this test also, the most favourable outcome was observed in the sample of the regenerated oils, while the used and new oils were not significantly different and are more toxic than the regenerated oil. A graph of the analysis is shown in Figure 5.

\section{Aerobic biodegradation with the manometric respiratory method}

The biodegradability test lasted 28 days with the same concentration of oil $(1 \mathrm{~g} / 1 \mathrm{~L}$ water $)$ as in the case of the ecotoxicological tests. The measuring head during the entire duration of the test recorded the amount of biodegradation of the organic pollution with mineral oils. After the test, these data 
Table 6 - Basic statistical characteristics of test results of growth inhibition of Sinapis alba root

\begin{tabular}{|c|c|c|c|c|c|}
\hline \multirow{2}{*}{$\begin{array}{l}\text { Sample concentration } \\
\qquad\left(\mathrm{mg} \mathrm{L}^{-1}\right)\end{array}$} & \multirow{2}{*}{ Mineral oil Turbinol } & \multirow{2}{*}{ Average inhibition (\%) } & \multirow{2}{*}{ Standard error } & \multicolumn{2}{|c|}{ Confidence intervals } \\
\hline & & & & $-95.00 \%$ & $+95.00 \%$ \\
\hline \multirow{3}{*}{40} & New & 55.79 & 8.10 & 39.90 & 71.68 \\
\hline & Used & 57.16 & 8.10 & 41.27 & 73.06 \\
\hline & After regeneration & 62.30 & 8.10 & 46.41 & 78.19 \\
\hline \multirow{3}{*}{20} & New & 57.85 & 8.10 & 41.96 & 73.74 \\
\hline & Used & 58.86 & 8.10 & 42.97 & 74.75 \\
\hline & After regeneration & 56.32 & 8.10 & 40.43 & 72.21 \\
\hline \multirow{3}{*}{10} & New & 54.71 & 8.10 & 38.82 & 70.60 \\
\hline & Used & 49.12 & 8.10 & 33.23 & 65.01 \\
\hline & After regeneration & 33.21 & 8.10 & 17.32 & 49.10 \\
\hline \multirow{3}{*}{6.7} & New & 54.12 & 8.10 & 38.23 & 70.01 \\
\hline & Used & 39.00 & 8.10 & 23.11 & 54.89 \\
\hline & After regeneration & 29.71 & 8.10 & 13.82 & 45.60 \\
\hline \multirow{3}{*}{5} & New & 27.31 & 8.10 & 11.42 & 43.20 \\
\hline & Used & 39.80 & 8.10 & 23.90 & 55.69 \\
\hline & After regeneration & 28.09 & 8.10 & 12.20 & 43.98 \\
\hline
\end{tabular}

Table 7 - Statistical model of the calculation of $I C_{50}$ for the growth inhibition of Sinapis alba root

\begin{tabular}{c|c|c|c|c}
\hline $\begin{array}{c}\text { Mineral oil } \\
\text { Turbinol }\end{array}$ & Statistical model & $A$ & $k$ & $\begin{array}{c}\mathrm{IC}_{50} \\
\left(\mathrm{mg} \mathrm{L}^{-1}\right)\end{array}$ \\
\hline Used & $y=A \cdot \exp (k \cdot x)$ & 40.4096 & 0.0106 & 20.09 \\
New & $y=A \cdot \exp (k \cdot x)$ & 40.7186 & 0.0104 & 19.74 \\
$\begin{array}{c}\text { After } \\
\text { regeneration }\end{array}$ & $y=A \cdot \exp (k \cdot x)$ & 26.8737 & 0.0237 & 26.20 \\
\hline
\end{tabular}

Note: $A$ - inhibition at zero concentration; $k$ - steepness of decline

were readings from the measuring heads using the controller OxiTop OC110. By using the program Achat, the data were transmitted into the computer and evaluated. Plots of the waveforms of the samples of oil contaminants in water are given in Figure 6.

In the biodegradation model of the sample contaminated with new oil, the degradation reached a level of $5.3 \%$ in the 14-day test, and by the end of the 28-day test, this value did not change. The microorganisms in the surface water were forced to adapt quickly (without a lag phase), and this is not shown in the statistical model during the degradation of the sample (Figure 6).

The growth phase (degradation phase) lasted 13 days before passing into stationary phase, which represents the maximum level of degradation.

The maximum level of degradation was that of the used oil in the aquatic medium, at $9 \%$, and the degradation process (phase of accelerated growth) stopped on the 17th day of the test and passed smoothly to stationary phase, which lasted until the end of the test.

In the samples contaminated with the regenerated oils, the degradation phase stopped on the $21 \mathrm{st}$ day and the maximum level of degradation of the stationary phase was $7.2 \%$ (Figure 7).

Boiko ${ }^{29}$ presented the absence of contaminants as an elementary quality requirement for turbine oil. Impurities may consist of water and organic compounds. Aging of mineral oils is caused by microbiological processes that occur in the oils because of the presence of free water. The free water allows the growth of microorganisms, which feed on the oil and reproduce as colonies over the surface of the free water.

The products of their vital activity are acids, which reduce the $\mathrm{pH}$ of the water and oil. The reaction in the acid medium of the metal facilitates the formation of bioemulsions and their precipitation in the form of sludge.

\section{Conclusion}

Regeneration of waste oils is an environmentally friendly solution to the renewal of their basic properties, which also helps reduce the volume of the hazardous waste they produce. Our research aimed at the determination and comparison of the 

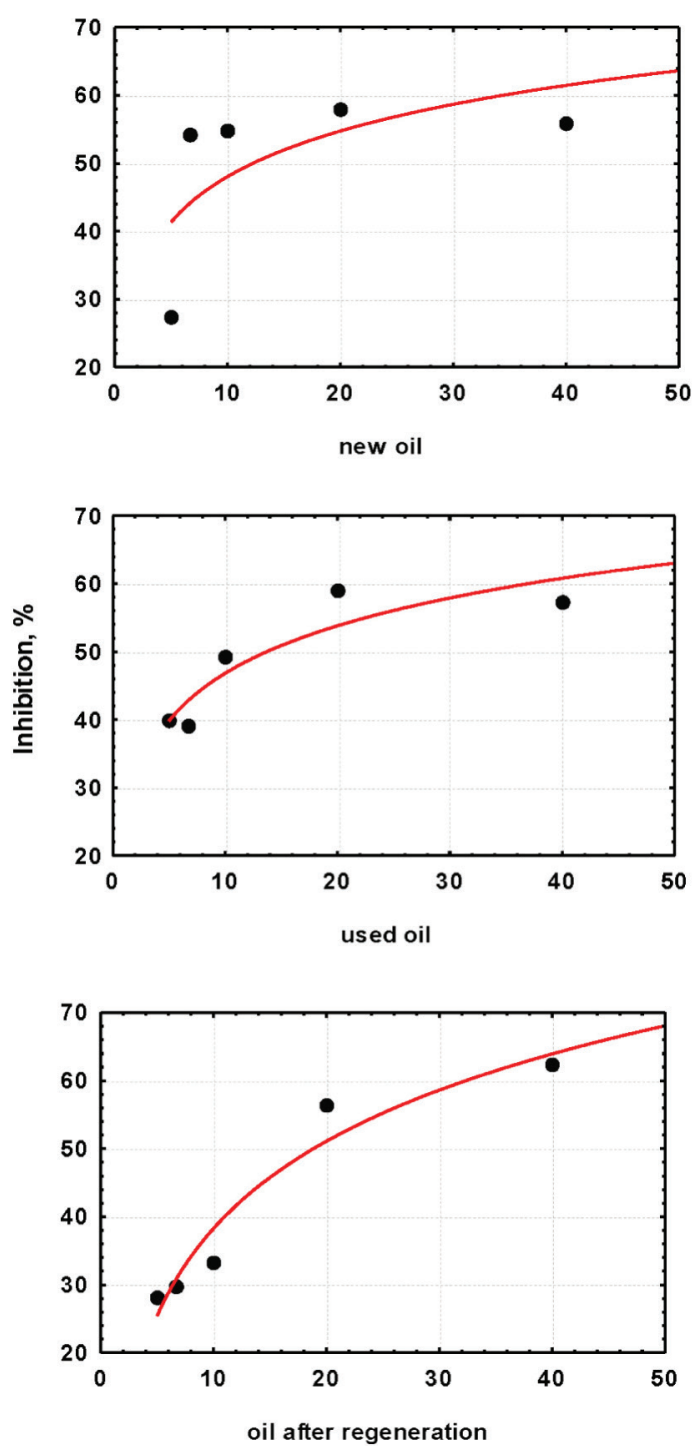

Concentration, $\mathrm{mg} \mathrm{L}^{-1}$

Fig. 5 - Regression analysis of growth inhibition of Sinapis alba root

composition of the mineral oil Turbinol X-EP 46: unused, used for one year, and electrostatically regenerated. From an overall assessment of the impact of wear and tear on the properties of the tested mineral oil Turbinol X-EP 46, it appears that the regeneration process of electrostatic precipitation has a positive impact on the ecotoxicological and biodegradation properties of oils. By eliminating the many products resulting from the use of the oil, the composition of the regenerated oil is similar to the composition of new oil, and we also assume that the process causes no significant changes to the required properties (viscosity, pour point, and other) in terms of the use of the oil in practice. From comparison of the inhibition of said products in the ecotoxicological tests of the model samples, we conclude that, in ecotoxicological terms, the used
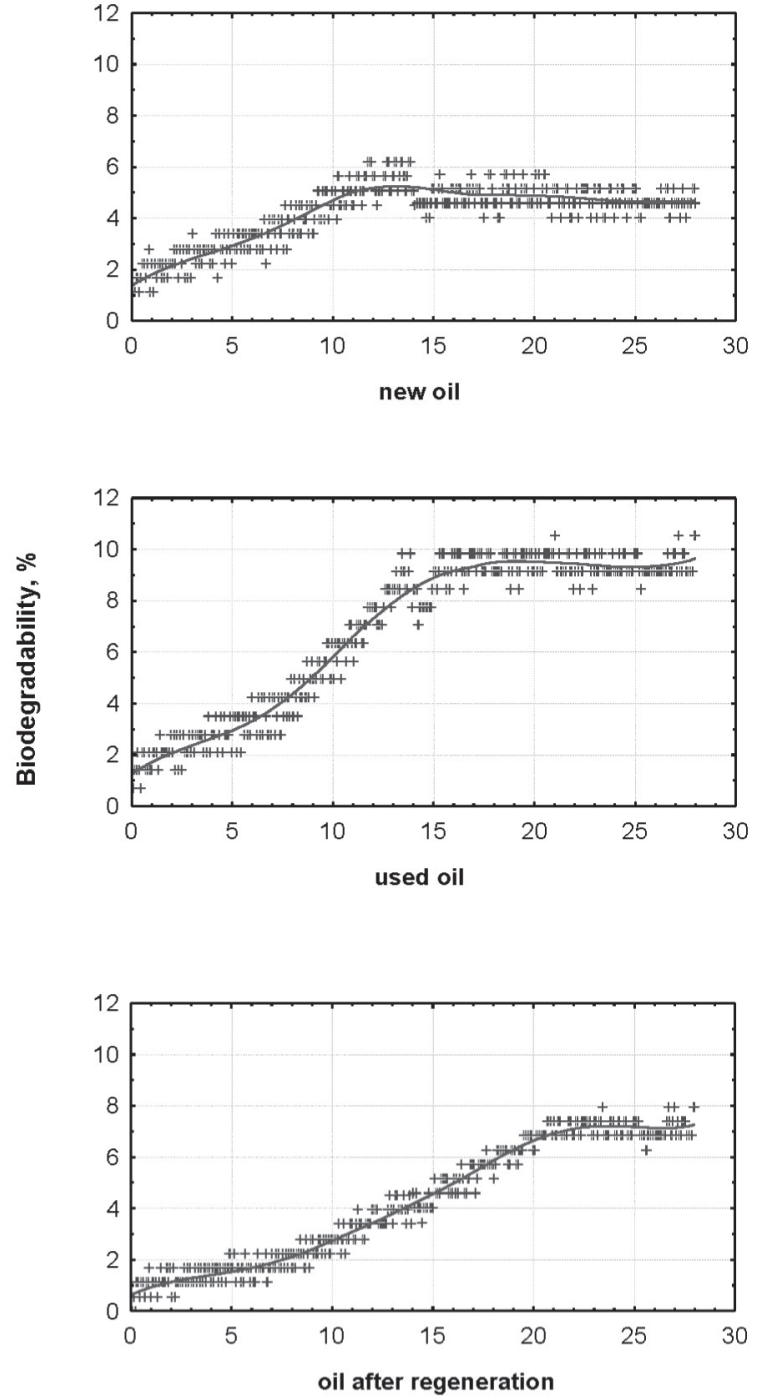

Time, days

Fig. 6 - Plot of biodegradability with time in the oil samples

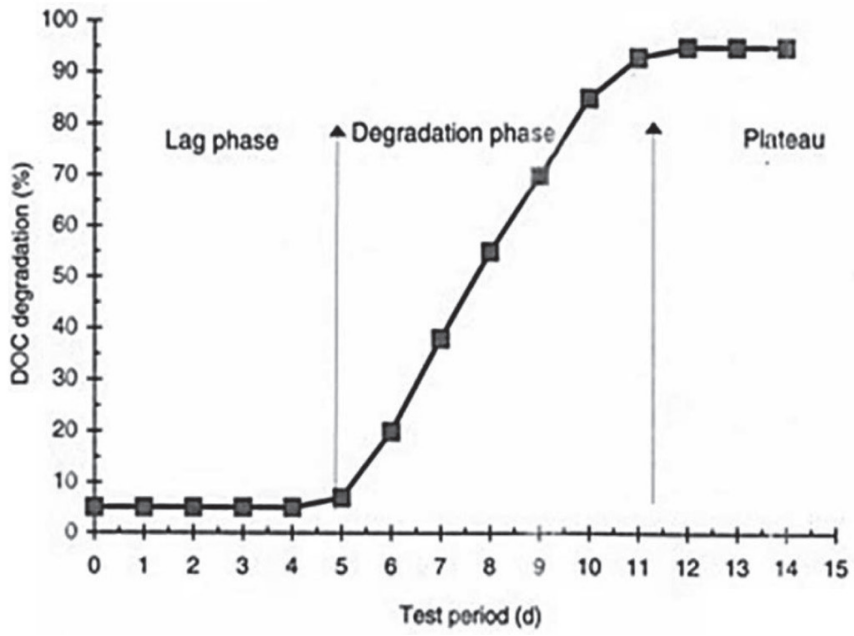

Fig. 7 -Degradation curve $e^{28}$ 
mineral oil possesses the worst characteristics and the regenerated oil has the best, although they are always toxic, given their petroleum origin. Providing that the ecotoxicological effects of the recovered oil are comparable to or more favorable than those of the new oil, oil regeneration is found to be an effective method. This is important in terms of saving raw material sources, but also in terms of reducing the environmental burden from the disposal of hazardous wastes, which include waste mineral oils. ${ }^{30}$ From the determination of biodegradability using the aerobic manometric respiratory method, where only natural microflora of the surface water participate was sed in the process of biodegradation, the result showed that individual samples are hard to biodegrade. Thus, for water as a component of the environment, this poses environmental risks.

\section{ACKNOWLEDGEMENTS}

This paper was published under the support of the Scientific grant of the Ministry of Education, Science, Research and Sport of the Slovak Republic, and the Slovak Academy of Sciences, grant VEGA 1/0826/15 and 1/0377/17.

\section{References}

1. Hybská, H., Samešová, D., Ollerová, H., Impact of organic pollutants on the environment.Technical University in Zvolen, 2015, pp. 52-69.

2. Tkáč, Z., Hujo, L., Tulik, J., Kosiba, J., Uhrinová, D., Šinský, V., Greening of agricultural and forestry tractors, Acta Universitatis Agriculturae et Silviculturae Mendelianae Brunensis 62 (2014) 1135.

3. Majdan, R., Tkáč, Z., Stančik, B., Abrahám, R., Štulajter, I., Ševčik, P., Rašo, M., Elimination of ecological fluids contamination in agricultural tractors, Research in Agricultural Engineering 60 (2014) 9.

4. Kučera, M., Aleš, Z., Ivandič, Ž., Hujo, L., Possibility of hydraulic fluids with a low environmental impact application in agriculture and transport machinery, Journal of Central European Agriculture 14 (2013) 1575. doi: https://doi.org/10.5513/JCEA01/14.4.1399

5. Lewtas, J., Air pollution combustion emissions: Characterization of causative agents and mechanisms associated with cancer, reproductive, and cardiovascular effects, Mutation Research 636 (2007) 95.

doi: https://doi.org/10.1016/j.mrrev.2007.08.003

6. Shogren, R., L., Petrovic, Z., Liu, Z., Erhan, S., Z., Biodegradation behavior of some vegetable oil-based polymers, J. Polym. Environ. 12 (2004) 173 doi: https://doi.org/10.1023/B:JOOE.0000038549.73769.7d

7. Hroncová, E., Ladomerský, J., Environmental analysis of hospital waste and carcasses treatment and disposal. Paper presented at International Conference on Engineering Science and Production Management, ESPM 2015; 16-17 April 2015; Tatranska Strba, High Tatras Mountains, Slovakia, pp. 467-474.

8. Saval, S., Bioremediation: clean-up biotechnologies for soils and aquifers. Environmental Biotechnology and Cleaner Bioprocesses. London, Taylor and Francis Limited, 2000, pp 155-166.
9. Landis, W. G., Yu, M. H., Introduction to environmental toxicology: impacts of chemicals upon ecological systems. Florida, Lewis Publishers, 1995, pp. 112-119.

10. Mariano, A. P., Kataoka, A. P. A. G., Angelis, D. F., Bonotto, D. M., Laboratory study on the bioremediation of diesel oil contaminated soil from a petrol station, Braz. J. Microbiol. 38 (2007) 346.

doi: https://doi.org/10.1590/S1517-83822007000200030

11. Lopes, P. R. M., Montagnolli, R. N., Domingue, R. F., Bidoia, E. D., Toxicity and biodegradation in sandy soil contaminated by lubricant oils, B Environ. Contam. Tox. 84 (2010) 454.

doi: https://doi.org/10.1007/s00128-010-9945-8

12. Tamada, I. S., Lopes, P. R. M., Montagnolli, R. N., Bidoia, $E$. D., Biodegradation and toxicological evaluation of lubricant oils, Braz. Arch. Biol. Technol. 55 (2012) 951. doi: https://doi.org/10.1590/S1516-89132012000600020

13. Basu, B., Singh, M. P., Kapur, G. S., Ali, N., Sastry, M. I. S., Jain, S. K., Srivastana, S. P., Bhatnagar, A. K., Prediction of biodegradability of mineral base oils from chemical composition using artificial neural networks, Tribol. 31 (1998) 159.

14. Cecutti, Ch., Agius, D., Ecotoxicity and biodegradability in soil and aqueous media of lubricants used in forestry applications, Bioresource Technology 99 (2008) 8492. doi: https://doi.org/10.1016/j.biortech.2008.03.050

15. Fargašová, A., Ecotoxicological bioassays, Publishing Perspekt, Bratislava, 2009, pp 32-38.

16. Renato, P. M. L., Bidoia, E. D., Evaluation of the biodegradation of different types of lubricant oils in liquid medium, Braz. Arch. Biol. Technol. 52 (2009) 1285 doi: https://doi.org/10.1590/S1516-89132009000500028

17. OECD 301F. (1992) Modified OECD screening Test: Guideline for Testing of Chemicals. Ready Biodegradability: Manometric Respirometry Test.

18. Karhu, M., Kaakinen, J., Kuokkanen, T., Rämö, J., Biodegradation of light fuel oils in water and soil as determined by the manometric respirometric method, Water, Air, Soil Pollut. 197 (2009) 3. doi: https://doi.org/10.1007/s11270-008-9752-6

19. URL:http://www.broughtonlubricants.co.uk/products/859bp-turbinol-x-ep-46.aspx (21.01.2017)

20. Ilčík, Š., Štollmann, V., Šmal, P., Oil treatment technology at the Technical University in Zvolen, Tribotechnika 3 (2010) 24

21. Government Regulation Slovak Republic no. 269/2010 Laying down the the requirements to achieve good water status.

22. Pavlok, B., Modern methods of purification of hydraulic oils, MM Industrial Spectrum 5 (2006) 66.

23. STN 83 8303:1999. Testing of dangerous properties of wastes. Ecotoxicity. Acute toxicity tests on aquatic organisms and growth inhibition tests of algae and higher cultivated plants.

24. Act of the National Council of the Slovak Republic no. 67/2010 Coll. on conditions for placing chemical substances and mixtures on the market and on amendments to certain acts (Chemical Act).

25. Vähäoja, P., Piltonen, P., Hyvönen, A., Niinimäki, J., Jalonen, J., Kuokkanen, T., Biodegradability studies of certain wood preservatives in groundwater as determined by the respirometric BOD OxiTop method, Water, Air and Soil Pollution 165 (2005) 313.

doi: https://doi.org/10.1007/s11270-005-6912-9 
26. Moret, S., Purcaro, G., Conte, L. S., Polycyclic aromatic hydrocarbons in vegetable oils from canned foods, European Journal of Lipid Science and Technology 107 (2005) 488 doi: https://doi.org/10.1002/ejlt.200501060

27. Lengyel, J., Cvengǒ́, J., Non-lubricant related compounds in used mineral oils, Petroleum and Coal 54 (2009) 237.

28. Pagga, U., The significance of standardized degradation tests in the testing of substances. 1st Symposium on Bio- logical Degradability. Ludwigshafen, Germany, 2000, pp $1-12$.

29. Boiko, A. Y., New methods and techniques for turbine oil cleaning, Chemical and Petroleum Engineering 41 (2005) 8329.

doi: https://doi.org/10.1007/s10556-006-0037-x

30. Act of the National Council of the Slovak Republic no. 79/2015 Coll. on waste. 